\title{
Practical, Office-based Interventions That Improve Care Today
}

\author{
Marjorie A. Bowman, MD, MPA, Anne Victoria Neale, PhD, MPH, \\ and Dean A. Seebusen, MD, MPH
}

This issue is devoted to practical information and interventions to enhance patient care. Fully explaining the richness of the articles to our readers in a short Editors' Note is sometimes difficult. This month we were struck by the large number of specific interventions that could be used directly in practice today, or in the near future, because they do not require much additional time or much additional cost. These interventions do require some learning — and perhaps some unlearning — but readers can use this issue to make changes tomorrow! We would love to hear from any readers who use this information and implement one or another of the actions; send your stories to jabfm@med.wayne.edu. ( $\mathrm{J}$ Am Board Fam Med 2015;28:1-4.)

We are always looking for practical solutions to patient difficulties-even more so when evidence suggests a successful intervention for common concerns that have no other easy solutions. Some interventions require the provider to do something a bit differently, whereas others require the involvement of multiple members of the practice team or are best assisted by system support. Table 1 highlights example interventions that can be started immediately.

\section{Interventions for the Individual Provider}

Physicians find some patient encounters difficult and may dread these office visits. Physicians who report many of these types of patient encounters are more likely to be dissatisfied in practice. In a randomized trial across 6 offices, Edgoose et $\mathrm{al}^{1}$ report the positive results of a structured, angstrelieving, reflective intervention used by the provider before and after these visits. "BREATHE" is the mnemonic used for the portion of the intervention before the visit, and "OUT" is the mnemonic for the portion used after the visit. We wonder whether "BREATHE OUT" may not only decrease provider angst but also improve patient care. This intervention is easy to perform, takes little time, and likely could assist clinicians (and patients) in many types of settings.

Conflict of interest: The authors are editors of the FABFM.
Given anecdotal experience of increased urinary retention rates in people with Down syndrome, Chicoine and Sulo ${ }^{2}$ prospectively completed postvoid urinary scans and identified the rate of urinary retention. Urinary frequency was the most common complaint associated with objective urinary retention. In another report, video capability of new phones has led to a practical way to learn and use the particle repositioning maneuver for benign paroxysmal positional vertigo, which is common in family medicine offices. ${ }^{11}$ In a brief report Kim et $\mathrm{al}^{12}$ present the outcomes of myofascial trigger point injections for nocturnal calf cramps among 12 patients; positive results indicate the need for larger randomized trials with appropriate placebo controls.

\section{Improvements for Practices-Because Primary Care Makes a Big Difference}

Primary care makes a difference! Using a complex statistical model with cohort data over 16 years, Smith et $\mathrm{al}^{13}$ provide supporting data that is strongly positive for both primary care and for the patientcentered medical home model. The authors examined the impact of primary care and, separately, the impact of the patient-centered medical home on blood pressure and glycemic outcomes over time. This study was completed in a system that cares for an Alaska Native/American Indian population, a group with a high prevalence of negative outcomes 
Table 1. Example Actions and Their Primary Intervention Level Suggested By This Issues' Articles

\begin{tabular}{|c|c|c|}
\hline Article & Potential Action & Primary Action Level \\
\hline Edgoose et $\mathrm{al}^{1}$ & Use the BREATHE OUT technique for difficult visits & Individual provider \\
\hline Chicoine \& Sulo ${ }^{2}$ & $\begin{array}{l}\text { Check for urinary retention in people with Down syndrome } \\
\text { complaining of urinary frequency }\end{array}$ & Individual provider \\
\hline Thom et $\mathrm{al}^{3}$ & $\begin{array}{l}\text { Train medical assistants as health coaches for chronic illness } \\
\text { medication adherence }\end{array}$ & Practice \\
\hline Phillips et $\mathrm{al}^{4}$ & $\begin{array}{l}\text { Use letters and phone calls to enhance adherence to breast and } \\
\text { colon cancer screening }\end{array}$ & Practice \\
\hline Scheck McAlearney et $\mathrm{al}^{5}$ & $\begin{array}{l}\text { Give this article to organizational leaders when implementing } \\
\text { EHRs }\end{array}$ & Individual provider \\
\hline Anderson et $\mathrm{al}^{6}$ & $\begin{array}{l}\text { Document and give ICD code for suicidal ideation and suicide } \\
\text { attempts to support appropriate future interventions }\end{array}$ & $\begin{array}{l}\text { Individual provider with system } \\
\text { support }\end{array}$ \\
\hline Crump $^{7}$ & $\begin{array}{l}\text { Document and give ICD code for birth history, in particular } \\
\text { preterm birth, to aid prognostication and early diagnosis of } \\
\text { associated illnesses }\end{array}$ & $\begin{array}{l}\text { Individual provider with system } \\
\text { support }\end{array}$ \\
\hline Chu et $\mathrm{al}^{8}$ & $\begin{array}{l}\text { Provide ongoing HIV care without referral to a specialized } \\
\text { center }\end{array}$ & Individual provider and practice \\
\hline Wohl $^{9}$ & Avoid intrapartum antibiotics unless clearly necessary & $\begin{array}{l}\text { Individual provider knowledge with } \\
\text { system support }\end{array}$ \\
\hline Rolfo $^{10}$ & $\begin{array}{l}\text { Explain to appropriate patients new targeted treatments for } \\
\text { lung cancer based on genetic markers }\end{array}$ & Individual provider knowledge \\
\hline
\end{tabular}

from hypertension and diabetes. In addition, in a side finding, patients who lived closer to the offices were healthier, and those who attended $>10$ nutrition and exercises classes had better blood pressure control.

This issue has 3 important articles that show specific practical practice interventions that make a difference: (1) implementing medical assistant coaching to increase medication adherence for chronic conditions; ${ }^{3}$ (2) sending letters and making phone calls to improve the uptake of preventive testing for cancer; ${ }^{4}$ and (3) effectively implementing electronic health records (EHR). ${ }^{5}$ Although we previously have never specifically recommended this, consider sending a copy of the latter article to others in your organization!

1. Common issues in primary care include both medication adherence and how to improve care by fully using the skills of all types of health workers in the patient-centered medical home. Thom et $\mathrm{al}^{3}$ tackle this issue in a trial of health coaching by medical assistants to improve medication adherence. Positive results give us hope for both chronic diseases and the value of the patient-centered medical home principles.

2. Another aspect of adherence, screening for early detection of breast cancer and colon cancers, was tackled by Phillips and coauthors. ${ }^{4}$ Common interventions include letters and automated calls; these authors compared these individual methods with a combination of both the letters and calls. The combination was more effective at increasing screening rates than either alone. The adherence rate increased more for breast than colon cancer.

3. Learning from success with EHRs, McAlearney et $\mathrm{al}^{5}$ used qualitative methods with individuals from 6 health care organizations across the country who were selected for their known high level of EHR implementation to identify both administrator and physician views on crucial aspects of deployment. Although legions of studies identify physician and practice difficulties when implementing EHRs, McAlearney et $\mathrm{al}^{5}$ provide a few tips for success, specifically that maximizing the physician interactional experience with the EHR is a must! Particularly interesting was a comment from an older physician lamenting that he was no longer seen as the expert in the practice-the experts are now the computersavvy younger physicians. No surprise for physicians, but read more for hints for your practice. For doctors struggling with EHRs, intervene by sending this article to your organization!

\section{Specific Documentation That Can Make a Difference}

We know that many diseases and problems identified in an office encounter are not documented by 
a diagnosis or International Classification of Diseases (ICD) code. As noted previously in $7 A B F M,{ }^{14}$ getting a diagnosis such as obesity on the problem list is frequently associated with an increased rate of appropriate interventions. Anderson et $\mathrm{al}^{6}$ found one of these problems-a very telling and scary problem that could mean life or death (suicide)using the extremely valuable and little understood research tool of natural language processing (NLP), in which computers search the actual office note rather than the identified EHR searchable fields, such as the Problem List that houses the ICD codes. As computers get more powerful, NLP will increasingly be used to tackle problems, and this article shows why. Only $3 \%$ of patients with suicidal ideation had a corresponding ICD code in their problem list and only $19 \%$ with a suicide attempt had it noted in their problem list. Given that suicide attempts are a major correlate of future suicides, this should be in the EHR to effect the intensity of medical care. Maybe someday NLP can actually create our problem lists for us!

Crump et $\mathrm{al}^{7}$ considered the importance of documenting preterm birth because of the long-term risk for negative outcomes, including early death and multiple diseases. In a fascinating discussion of the impact of birth history, we are reminded of why we need to include preterm birth as part of a patient's documented history. Perhaps EHRs will help more than memories (which are often unreliable). People often do not know if they were born preterm, so early documentation is needed, starting at the first office visit in a neonate's life.

\section{Specific Health Concerns}

Chu et $\mathrm{al}^{8}$ noted that community-based care by family physicians and general internists provided HIV virologic suppression similar to that of hospital-based care provided by infectious disease specialists. The analysis was adjusted for known risk factors for lack of HIV control, and the rate was better in unadjusted primary care data. Primary care physicians may not be surprised by these results, but, unfortunately, others must be or this type of research would not be conducted. The quality of care provided by primary care physicians is often underestimated.

Wohl et $\mathrm{al}^{9}$ contribute to the recent awareness of the possibility that intrapartum antibiotics have long-term outcomes, perhaps specifically for aller- gic diseases. ${ }^{15}$ The data presented here raise the possibility that antibiotics for $>24$ hours is associated with atopic dermatitis, but they are not definitive, and more study is needed. Obviously, antibiotics should not be used without a clear and important clinical reason.

Gastric bypass leads to significant changes in food intake and usually significant weight loss. This substantial life change affects the family as well as the patient. It does not seem like a great leap to think that the family may also change their dietary habits and thus lose weight. Aarts et $\mathrm{al}^{16}$ found that while over half of partners of patients who underwent gastric bypass did lose weight in the following year, it was not inevitable.

\section{Clinical Cases, Conundrums, and Reviews}

We have several educational cases and clinical reviews. Rolfo et $\mathrm{al}^{10}$ provide an excellent update on the changing fate of lung cancer, and the world of genetics is the reason. Some lung cancers can now be identified by mutations and treated with specific medications. Survival rates have improved dramatically, although the final outcomes are not yet known. A second review by Owensby et $\mathrm{al}^{17}$ is on the management of upper gastrointestinal bleeding in children.

We have specific conundrum cases that call on our ability to carefully evaluate patients to avoid negative outcomes or unnecessary interventions. First, Estimable et $\mathrm{al}^{18}$ present a case of acute longus colli calcific tendinitis; the correct diagnosis avoided a potentially difficult intervention. Lozano et $\mathrm{al}^{19}$ provide a case description and a basic review of Staphylococcus epidermidis in urine in children, when assuming a benign course could be wrong. And, when mania rears up in the context of quetiapine, is it a case of too little quetiapine, or was the mania caused by the quetiapine? Read the case described by Millard et $\mathrm{al}^{20}$ and see what you think, but also learn that low-dose quetiapine is thought to possibly initiate mania.

\section{Data That Should Make Clinicians Think \\ Twice}

Overall, Koti and Roetzheim ${ }^{21}$ found high consistency in blood pressure interventions in practice recommended by JNC $7 .^{22}$ However, the authors found differences in implementation by patient sex, marital status, and type of health insurance. These 
variations should prompt reflection to improve care more consistently for all patients. Reddy et $\mathrm{al}^{23}$ provide a reminder to particularly consider family planning for women with cardiac risk factors, given that they may need different types of birth control methods and because of the increased potential for pregnancy and birth complications.

\section{References}

1. Edgoose JYC, Regner CJ, Zakletskaia LI. BREATHE OUT: a randomized controlled trial of a structured intervention to improve clinician satisfaction with difficult visits. J Am Board Fam Med 2015;28:13-20.

2. Chicoine B, Sulo S. Rate of urinary retention in adults with Down syndrome: a prospective study. J Am Board Fam Med 2015;28:115-7.

3. Thom DH, Willard-Grace R, Hessler D, et al. The impact of health coaching on medication adherence in patients with poorly controlled diabetes, hypertension, and/or hyperlipidemia: a randomized controlled trial. J Am Board Fam Med 2015;28:38-45.

4. Phillips L, Hendren S, Humiston S, Winters P, Fiscella K. Improving breast and colon cancer screening rates: a comparison of letters, automated phone calls, or both. J Am Board Fam Med 2015;28: 46-54.

5. Scheck McAlearney A, Hefner JL, Sieck C, Rizer M, Huerta TR. Fundamental issues in implementing an ambulatory care electronic health record. J Am Board Fam Med 2015;28:55-64.

6. Anderson HD, Pace WD, Brandt E, et al. Monitoring suicidal patients in primary care using electronic health records. J Am Board Fam Med 2015;28: 65-71.

7. Crump C. Birth history is forever: implications for family medicine. J Am Board Fam Med 2015;28: 121-3.

8. Chu C, Heo M, Peshansky A, et al. Comparable sustained virologic suppression between community- and academic-based HIV care settings. J Am Board Fam Med 2015;28:72-81.

9. Wohl DL, Curry WJ, Mauger D, Miller J, Tyrie K. Intrapartum antibiotics and childhood atopic dermatitis. J Am Board Fam Med 2015;28:82-9.

10. Rolfo C, Passiglia F, Ostrowski M, et al. Improvement in lung cancer outcomes with targeted therapies: an update for family physicians. J Am Board Fam Med 2015;28:124-33.

11. Organ B, Liu H, Bromwich M. An iPhone-assisted particle repositioning maneuver for benign paroxysmal positional vertigo (BPPV): a prospective ran- domized study. J Am Board Fam Med 2015;28: 118-20.

12. Kim D-H, Yoon DM, Yoon KB. The effects of myofascial trigger point injections on nocturnal calf cramps. J Am Board Fam Med 2015;28:21-7.

13. Smith JJ, Berman MD, Hiratsuka VY, Frazier RR. The effect of regular primary care utilization on long-term glycemic and blood pressure control in adults with diabetes. J Am Board Fam Med 2015;28: $28-37$.

14. Waring ME, Roberts MB, Parker DR, Eaton CB. Documentation and management of overweight and obesity in primary care. J Am Board Fam Med 2009; 22:544-52.

15. Russell SL, Gold MJ, Reynolds LA, et al. Perinatal antibiotic-induced shifts in gut microbiota have differential effects on inflammatory lung diseases. J Allergy Clin Immunol 2014 Aug 8. [Epub ahead of print]. Available from: http://www.jacionline.org/ article/S0091-6749(14)00893-8/abstract. Accessed December 17, 2014.

16. Aarts F, Radhakishun NNE, van Vliet $M$, et al. Gastric bypass may promote weight loss in overweight partners. J Am Board Fam Med 2015;28: 90-96.

17. Owensby S, Taylor K, Wilkins T. Diagnosis and management of upper gastrointestinal bleeding in children. J Am Board Fam Med 2015;28:134-45.

18. Estimable K, Rizk C, Pujalte GG. A rare case of neck pain: acute longus colli calcific tendinitis in a possibly immunocompromised individual. J Am Board Fam Med 2015;28:146-50.

19. Lozano V, Fernandez G, Hatch R, Spencer PL, Taylor SL. Staphylococcus epidermidis in urine is not always benign: a case report of pyelonephritis in a child. J Am Board Fam Med 2015;28:151-3.

20. Millard H, Wilson BA, Noordsy DL. Low-dose quetiapine induced or worsened mania in the context of possible undertreatment. J Am Board Fam Med 2014;28:154-8.

21. Koti A, Roetzheim RG. Patient factors associated with documented provision of JNC 7-recommended hypertension care at an academic family medicine office. J Am Board Fam Med 2015;28:97-104.

22. Chobanian AV, Bakris GL, Black HR, et al. Seventh report of the Joint National Committee on Prevention, Detection, Evaluation, and Treatment of High Blood Pressure. Hypertension 2003;42:1206-52.

23. Reddy SM, Ramachandran A, Cabral H, Kazis L. Provision of family planning to women with cardiovascular risk factors. J Am Board Fam Med 2015;28: 105-14. 